\title{
DETERIORAÇÃO, ENDURECIMENTO E ANORMALIDADES EM SEMENTES E PLÂNTULAS DE ALGODOEIRO HERBÁCEO (Gossypium hirsutum L. r. latifolium H.) SOB ESTRESSE HÍDRICO ${ }^{1}$
}

\author{
José Rodrigues Pereira ${ }^{2}$, Pedro Dantas Fernandes ${ }^{3}$ \\ e Napoleão Esberard de Macêdo Beltrão ${ }^{4}$
}

\begin{abstract}
RESUMO
Conduziu-se um experimento em laboratório, com o objetivo de se estudar o comportamento germinativo de sementes de 10 genótipos de algodoeiro herbáceo (Gossypium hirsutum L. r. latifolium H.) de fibras médias, de promissora potencialidade produtiva e tecnológica, e identificar os mais e os menos sensíveis em baixos níveis de potencial osmótico $(0.0,-0.2,-0.4,-0.6,-0.8$ e-1.0MPa), simulados por polietileno glicol-6000; foi utilizado papel Germitest, num delineamento inteiramente casualizado, em esquema fatorial $10 \times 6$, com 4 repetições, cada uma contendo 50 sementes. Foram verificadas diferenças de comportamento entre os genótipos de algodoeiro herbáceo estudados nos diversos níveis de estresse hídrico; a percentagem de sementes deterioradas e de plântulas anormais, nos dez genótipos, diminuiu mas a de sementes duras aumentou, nos níveis de maior concentração de PEG-6000. As cultivares CNPA Precoce 2 e CNPA Precoce 1 são as menos sensíveis a baixos potenciais osmóticos (-0,6 e -0,8MPa), enquanto LG ROGERS e CNPA 7H são medianamente sensíveis. A linhagem CNPA 86-1195-1 é a mais afetada.
\end{abstract}

Palavras chave: potencial hídrico, simulação de seca, PEG-6000, germinação

\author{
DETERIORATION, HARDENING AND ABNORMALITIES IN SEEDS \\ AND SEEDLINGS OF UPLAND COTTON (Gossypium hirsutum L. r. latifolium H.) \\ GENOTYPES UNDER WATER STRESS
}

\begin{abstract}
With the objective os studying the behavior of germination of the best ten genotypes developed by Embrapa Breeding Program of upland cotton (Gossypium hirsutum L. race latifolium H.) of media fibers, and to identify the more and the less sensitive, in six levels of the osmotic potential $(0.0,-0.2$, $-0.4,-0.6,-0.8$ and $-1.0 \mathrm{MPa}$ ), induced by polyethylene glycol-6000, a trial in laboratory was carried out, making use of the Germitest paper, in a experimental design completely randomized, in a $10 \times 6$ factorial scheme, with 4 replications, each consisting of 50 seeds. There was difference of behavior between the genotypes in study of cotton, between different water stress levels. The percentage of deteriorated seeds and abnormal seedlings, on ten genotypes declined, but the percentage of seeds without absorption of water increased, in the major PEG-6000 concentration levels. The cultivars

\footnotetext{
${ }^{1}$ Parte da dissertação de Mestrado do primeiro autor apresentada à Universidade Federal da Paraíba

${ }^{2}$ Engenheiro Agrônomo, M.Sc, Embrapa, Algodão, R. Osvaldo Cruz 1143, Centenário, CEP 58107-720, Campina Grande, PB, fone (083)341-3608, fax (083)322-7751. E-mail: rodrigues@ cnpa.embrapa.br

${ }^{3}$ Doutor, Professor do DEAg/CCT/UFPB, Av. Aprígio Veloso 882, Bodocongó, CEP 58109-970, Campina Grande, PB, fone (083)310-1055. E-mail: copeag@ deag.ufpb.br

${ }^{4}$ Ph.D., Pesquisador da Embrapa Algodão. E-mail: algodão@cnpa.embrapa.br
} 
CNPA Precoce 2 and CNPA Precoce 1 are the less sensitive to reduced osmotic potentials (-0.6 and $-0.8 \mathrm{MPa}$ ), while LG ROGERS and CNPA $7 \mathrm{H}$ are more or less sensitive. The lineage CNPA 86-1195-1 is the most sensitive.

Key words: water potential, drought simulation, PEG-6000, germination

\section{INTRODUÇÃO}

No Nordeste, o agronegócio do algodão, com o crescimento e modernização do parque têxtil, tem merecido atenção dos governos quanto ao aspecto irrigação, buscando aplicativos tecnológicos para incremento nos rendimentos e nas taxas de retorno (Barreto et al.1997).

O algodoeiro herbáceo (Gossypium hirsutum, L. r. latifolium H.) é uma das principais alternativas para a agricultura do semiárido brasileiro, mas para que as cultivares externem, em termos de produção, o seu potencial genético, é importante explorá-las em locais que apresentem condições edafoclimáticas aptas ao seu crescimento e desenvolvimento (Amorim Neto et al.1997).

O grau de umidade, no momento da semeadura, regula a quantidade de água a ser absorvida pela semente até atingir o nível necessário à germinação; cada fator deve ser considerado para não haver prejuízos à população desejada de plantas e não serem as sementes injuriadas durante a fase de embebição, resultando em plântulas normais e vigorosas que garantam o estabelecimento da cultura (Nóbrega \& Rodrigues, 1995).

Para Bewley \& Black (1985), a água é o fator que exerce maior influência sobre o processo de germinação de sementes; quando o potencial de água no meio externo é reduzido, em níveis altamente adversos, não há germinação, afetando o estabelecimento e a produção das culturas (Hunter \& Erickson, 1952; Evans \& Stickler, 1961; Jensen, 1971; Singh \& Singh, 1983a).

A tolerância ao déficit hídrico é uma característica importante em qualquer cultivo, por se relacionar com a possibilidade de se ter produção em áreas áridas e semi-áridas. Urge, portanto, identificar genótipos tolerantes, ou até mesmo resistentes, ao déficit hídrico no solo e às condições adversas do meio ambiente (Fiegenbaum et al.1991).

Uma solução pode estar no melhoramento genético, outra no uso de produtos químicos para simulação de estresse hídrico na planta (Lawlor, 1970); a última alternativa constitui-se num caminho mais rápido, permitindo a simulação de estresse hídrico em condições de laboratório. Entre os produtos químicos mais usados, incluem-se cloreto de sódio (Parmer \& Moore, 1968; Sharma, 1973 e 1976; Lopes et al. 1989), manitol (Evans \& Stickler ,1961; Parmer \& Moore, 1968; Lopes et al. 1989), sulfato de sódio (Campos \& Assunção, 1990) e polietileno glicol (Parmer \& Moore, 1968; Sharma, 1976; Hadas, 1977); dentre eles, destaca-se o polietileno glicol (PEG) ou lutrol, comercialmente conhecido como Carbowax, um polímero químico de cadeia longa, inerte, não iônico, altamente solúvel em água. Pode ser usado como agente osmótico, pois não interfere nos processos metabólicos dos vegetais (Lagerwerff et al. 1961; Levitt, 1972).

Nos últimos anos, o polietileno glicol-6000 tem sido indicado para pesquisas agronômicas, em laboratório e em casa de vegetação, onde é possível um controle mais efetivo do ambiente, por ser o soluto osmótico mais satisfatório para simulação de estresse hídrico no meio externo, solo ou solução (Mexal et al.
1975; Bradford, 1986; Nogueira \& Nagai, 1988), constituindo-se numa alternativa muito importante para estudo do efeito de estresse hídrico na germinação das sementes e, subseqüentemente, no crescimento da plântula (Lagerwerff et al., 1961).

Segundo Lawlor (1970), o PEG é um agente com capacidade de aumentar a concentração osmótica das soluções nutritivas utilizadas em experimentos com plantas; tem a capacidade de simular seca, causando dissecação na planta, por bloquear o movimento da água pela diminuição do potencial hídrico do meio onde crescem as raízes.

Hadas (1977) sugere o uso de soluções de PEG em testes padrão de germinação para estimativas do desempenho da germinação da semente em condições de campo.

Considerando-se que existem poucas informações, na literatura disponível, sobre o emprego do polietileno glicol-6000 e seus efeitos na germinação de sementes de algodoeiro, este trabalho teve por objetivo estudar o comportamento de dez genótipos de algodoeiro herbáceo, submetidos ao déficit hídrico simulado por PEG 6000, na fase de germinação, identificando-se os mais e os menos sensíveis.

\section{MATERIAL E MÉTODOS}

O ensaio foi conduzido no Laboratório de Análises de Sementes da Embrapa Algodão, no período de julho a dezembro de 1996.

Foram utilizadas sementes de dez genótipos de algodoeiro herbáceo, constantes do Ensaio Regional de algodoeiro herbáceo de fibras médias. As soluções de PEG-6000 foram preparadas obedecendo tabela contida em Villela et al. (1991).

O delineamento experimental foi o inteiramente casualizado, em esquema fatorial $10 \times 6$, com 4 repetições, totalizando 60 tratamentos, sendo os fatores: genótipos de algodoeiro herbáceo $\left(\mathrm{G}_{1} \rightarrow\right.$ CNPA $7 \mathrm{H} ; \mathrm{G}_{2} \rightarrow$ CNPA Precoce $1 ; \mathrm{G}_{3} \rightarrow$ CNPA Precoce $2 ; \mathrm{G}_{4} \rightarrow \mathrm{IAC} 22 ; \mathrm{G}_{5} \rightarrow \mathrm{CNPA} 87-62 ; \mathrm{G}_{6} \rightarrow$ CNPA 87-33; $\mathrm{G}_{7}$ $\rightarrow$ CNPA 87-24; $\mathrm{G}_{8} \rightarrow$ LG ROGERS ; $\mathrm{G}_{9} \rightarrow$ CNPA 86-1195-1 e $\mathrm{G}_{10} \rightarrow$ CNPA 86-1190-5) e níveis de potenciais osmóticos $\left(\mathrm{N}_{1} \rightarrow 0,0 \mathrm{MPa} ; \mathrm{N}_{2} \rightarrow-0,2 \mathrm{MPa} ; \mathrm{N}_{3} \rightarrow-0,4 \mathrm{MPa} ; \mathrm{N}_{4} \rightarrow-0,6 \mathrm{MPa}\right.$; $\mathrm{N}_{5} \rightarrow-0,8 \mathrm{MPa}$ e $\mathrm{N}_{6} \rightarrow-1,0 \mathrm{MPa}$ ).

Foram seguidos os procedimentos descritos nas Regras para Análises de Sementes (Brasil, 1992). Todas as folhas de papel Germitest necessárias aos testes, em cada nível de potencial osmótico estudado, eram simultaneamente umedecidas em solução. Na instalação dos testes, sobre duas folhas do papel, superpostas, foram distribuídas 50 sementes de cada genótipo, por repetição, em sete fileiras eqüidistantes, com sete sementes cada uma, e mais uma delas colocada no centro; uma terceira folha do referido papel foi utilizada como cobertura protetora; em seguida, o conjunto foi enrolado e amarrado, anotando-se o respectivo tratamento e repetição. Acomodados os cartuchos em recipientes de plástico, cada qual contendo as quatro repetições de cada genótipo, colocou-se o conjunto no 
germinador, regulado à temperatura preestabelecida $\left(27^{\circ} \mathrm{C}\right) \mathrm{e}$, no decorrer do experimento, o conjunto foi umedecido com a respectiva solução de PEG-6000, de modo a se manter os níveis desejados de potenciais osmóticos.

A avaliação do teste de germinação foi efetivada com pequenas modificações, segundo as Regras para Análises de Sementes (Krzyzanowski et al. 1991; Brasil, 1992), relativas à cultura do algodão (Gossypium spp.): fez-se uma contagempadrão das plântulas (sementes germinadas), no $12^{\circ}$ dia, e uma contagem adicional, no $20^{\circ}$ dia, por se tratar de simulação de déficit hídrico crescente, o qual retarda a germinação das sementes; só na contagem final ( $20^{\circ}$ dia) é que se determinou o número e o respectivo percentual de sementes deterioradas e de sementes duras.

Nas contagens, foram consideradas: germinadas, as sementes que originaram plântulas com estruturas essenciais (radícula, epicótilo, hipocótilo) bem diferenciadas, sadias e desenvolvidas (plântulas normais) e com um comprimento mínimo de radícula de $5 \mathrm{~mm}$; plântulas anormais, as que apresentavam qualquer uma das suas estruturas essenciais ausentes, deformadas, muito danificadas ou infectadas por patógenos da própria semente (Krzyzanowski et al. 1991; Brasil, 1992); deterioradas, as sementes que, ao final dos testes, não estavam duras nem dormentes, mas com uma coloração escuro intensa, anormal, parcial ou totalmente podres (Mata et al. 1985); e duras, as sementes que permaneceram sem absorver água (não entumecidas) até o final dos testes (Almeida et al. 1985; Brasil, 1992).

Os resultados, em percentagem, foram transformados em arco seno $(\mathrm{P} / 100)^{1 / 2}$ para homogeneizar as variâncias dos erros experimentais (Banzatto \& Kronka, 1989). Os dados, cumulativamente obtidos até a $3^{\mathrm{a}}$ contagem, foram submetidos às análises de variância (dados transformados) e de regressão polinomial (dados originais), enquanto as médias dos genótipos, em estudo, foram comparadas pelo teste de Tukey, a 5\% de probabilidade.

\section{RESULTADOS E DISCUSSÃO}

Analisando-se a Tabela 1, verificam-se efeitos significativos $(\mathrm{p}<0,01)$ para genótipos $(\mathrm{G})$, níveis de potencial osmótico $(\mathrm{N})$ simulados pelo PEG-6000 e para a interação $(\mathrm{G} \times \mathrm{N})$, tanto para o percentual médio de plântulas normais e anormais como para o de sementes deterioradas e duras; portanto, os dez genótipos de algodoeiro herbáceo estudados diferem na capacidade de germinar, quando submetidos às diferentes condições de estresse hídrico.

Tabela 1. Quadrado médio ${ }^{1}$ das percentagens de sementes deterioradas e duras e de plântulas anormais do teste de germinação de dez genótipos de algodoeiro herbáceo, em seis níveis de polietileno glicol-6000

\begin{tabular}{lrrrr}
\hline Fonte de Variação & \multicolumn{2}{c}{ Plântulas $^{2}$} & \multicolumn{2}{c}{ Sementes $^{2}$} \\
& Normais & Anormais & Deterioradas & \multicolumn{1}{c}{ Duras } \\
\hline Genótipos (G) & $279,06 * *$ & $347,45 * *$ & $231,31 * *$ & $301,26 * *$ \\
Níveis (N) & $22197,61 * *$ & $1203,36 * *$ & $1073,85 * *$ & $31253,96 * *$ \\
Interação (G x N) & $94,23 * *$ & $66,96 * *$ & $36,67 * *$ & $87,04 * *$ \\
\hline CV (\%) & 13,45 & 35,06 & 14,85 & 12,65 \\
\hline${ }^{1}$ Dados transformados em arco seno (P/100) ${ }^{1 / 2}$ \\
${ }^{2}$ 3 contagem do teste de germinação (20 dia após semeadura) \\
${ }^{\left({ }^{* *}\right)}$ Significativo a nível de 0,01 de probabilidade (Teste F) \\
$\begin{array}{l} \\
\text { R. Bras. Eng. Agríc. Ambiental, Campina Grande, v.2, n.2, p.186-194, 1998 }\end{array}$
\end{tabular}

As diferenças observadas entre os dez genótipos dentro de cada nível de potencial osmótico (Tabelas 2 a 5) devem-se, certamente, às variações de origem genética; pelo vigor genético explica-se por que alguns genótipos são mais sensíveis a condições adversas, como déficit hídrico, inclusive numa mesma espécie (Evans \& Stickler, 1961; Jensen, 1971; Popinigis, 1977; Carvalho \& Nakagawa, 1980).

\section{Plântulas anormais}

Como praticamente não houve diferenças no percentual de plântulas normais e anormais dos genótipos em análise da $2^{\mathrm{a}}$ para a $3^{\mathrm{a}}$ contagem do teste de germinação, será discutida, aqui, apenas a última contagem. Do mesmo modo, não se discutirá, em separado, neste trabalho, a variável percentual de plântulas normais (germinação) e, a inclusão da tabela respectiva (Tabela 2) serve apenas para se visualizar as relações com as demais variáveis do teste padrão de germinação, aqui discutidas.

Após desdobramento da interação, os dados de percentagem de plântulas anormais, na $3^{\mathfrak{a}}$ contagem do teste de germinação, estão organizados na Tabela 3.

Nota-se, inicialmente, tendência de aumento da percentagem de anormalidades, com o aumento da concentração de PEG, do nível $\mathrm{N}_{1}$ para os níveis $\mathrm{N}_{2}, \mathrm{~N}_{3}$ e $\mathrm{N}_{4}$, mas a partir do nível seguinte, os valores convergem decrescentemente; a razão da pequena taxa de anormalidades no nível testemunha $\left(\mathrm{N}_{1}\right)$, onde se utilizou apenas água destilada $(0,0 \mathrm{MPa})$, deve-se, provavelmente, ao fato da instalação desse tratamento ter sido feita logo que as sementes chegaram de Souza, PB, cujas condições ambientes são pouco favoráveis à proliferação de patógenos; além disso, neste nível de estresse a maioria das sementes dos vários genótipos ficou bem menos tempo sob a ação de patógenos, pois elas germinaram até a primeira contagem (4ํ dia póssemeadura); deduz-se, ainda, que até o $\mathrm{N}_{4}$ houve disponibilidade de água para absorção pelas sementes e, consequentemente, para a germinação (Tabela 2 e Tabela 3 ) e para a proliferação de patógenos que infectaram as sementes, causando lesões generalizadas por quase toda a plântula; complementa-se que, a partir do $\mathrm{N}_{5}$, a percentagem de germinação caiu drasticamente (Tabela 2) e, do mesmo modo, o índice de anormalidades (Tabela 3), pela limitada disponibilidade de água para absorção pelas sementes nos mais baixos potenciais osmóticos (Figura 1).

Tais evidências assemelham-se às proposições de Metivier (1979) de que, quando a concentração do soluto aumenta, a taxa de embebição diminui, devido a efeitos osmóticos; do mesmo modo, Parmer \& Moore (1968) trabalhando com polietileno glicol-6000, manitol e $\mathrm{NaCl}$ sobre sementes de milho, observaram retardamento e redução da germinação e da quantidade de água absorvida, com o aumento do potencial osmótico da solução.

Nienow et al. (1991), por sua vez, estudando os efeitos de soluções de PEG (600 e 6000) na germinação de sementes de alho verificaram, contrariamente, aumento do número de plântulas anormais.

Queiroz (1995) submetendo sementes de dez cultivares de feijão a seis níveis de tensão osmótica observou, também, que o índice de anormalidades aumentava com o nível de PEG-6000.

Mexal et al. (1975) citam que a solubilidade e a disponibilidade de $\mathrm{O}_{2}$ nas soluções de polietileno glicol diminuem com o aumento do peso molecular e da sua concentração, resultando em maior percentual de anormalidades em plantas. No presente caso, cujas anormalidades consistiam, basicamente, de lesões resultantes da infecção das plântulas por patógenos, o oxigênio não deve ter se tornado limitante, já que houve multiplicação, até excessiva, de patógenos nas cultivares CNPA Precoce 1 e CNPA Precoce 2, no nível de maior estresse da $3^{\underline{a}}$ contagem. 


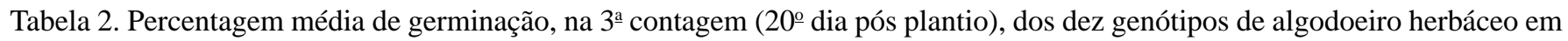
seis níveis de polietileno glicol-6000

\begin{tabular}{|c|c|c|c|c|c|c|}
\hline \multirow[t]{2}{*}{ Genótipos } & \multicolumn{6}{|c|}{ Níveis de PEG-6000 (MPa) } \\
\hline & 0,0 & $-0,2$ & $-0,4$ & $-0,6$ & $-0,8$ & $-1,0$ \\
\hline \multirow[t]{2}{*}{ 1. CNPA $7 \mathrm{H}$} & $62,46 a b c$ & $47,90 \mathrm{bc}$ & $46,43 \mathrm{ab}$ & $38,27 \mathrm{abc}$ & $19,60 \mathrm{ab}$ & 0,00 \\
\hline & $(78,62)$ & $(55,05)$ & $(52,49)$ & $(38,36)$ & $(11,25)$ & $(0,00)$ \\
\hline \multirow[t]{2}{*}{ 2. CNPA Precoce 1} & $50,13 d$ & $44,43 \mathrm{c}$ & $46,43 \mathrm{ab}$ & $41,82 \mathrm{a}$ & $27,22 \mathrm{a}$ & 2,03 \\
\hline & $(58,91)$ & $(49,01)$ & $(52,49)$ & $(44,46)$ & $(20,92)$ & $(0,13)$ \\
\hline \multirow[t]{2}{*}{ 3. CNPA Precoce 2} & $67,74 \mathrm{ab}$ & $58,60 \mathrm{ab}$ & $54,64 a$ & $43,27 \mathrm{a}$ & $28,09 a$ & 0,00 \\
\hline & $(85,65)$ & $(72,85)$ & $(66,51)$ & $(46,98)$ & $(22,17)$ & $(0,00)$ \\
\hline \multirow[t]{2}{*}{ 4. IAC 22} & $63,50 \mathrm{abc}$ & $53,44 a b c$ & $57,18 \mathrm{a}$ & $30,87 \mathrm{bcd}$ & $13,13 b c$ & 0,00 \\
\hline & $(80,09)$ & $(64,52)$ & $(70,62)$ & $(26,33)$ & $(5,16)$ & $(0,00)$ \\
\hline \multirow[t]{2}{*}{ 5. CNPA $87-62$} & $66,14 \mathrm{ab}$ & $47,33 \mathrm{c}$ & $46,74 \mathrm{ab}$ & $27,85 \mathrm{~cd}$ & $12,67 \mathrm{bc}$ & 0,00 \\
\hline & $(83,64)$ & $(54,06)$ & $(53,04)$ & $(21,82)$ & $(4,81)$ & $(0,00)$ \\
\hline \multirow[t]{2}{*}{ 6. CNPA $87-33$} & $62,71 \mathrm{abc}$ & $52,87 \mathrm{abc}$ & $46,76 a b$ & $30,14 \mathrm{bcd}$ & $7,61 \mathrm{c}$ & 0,00 \\
\hline & $(78,98)$ & $(63,56)$ & $(53,07)$ & $(25,21)$ & $(1,75)$ & $(0,00)$ \\
\hline \multirow[t]{2}{*}{ 7. CNPA $87-24$} & $57,12 \mathrm{bcd}$ & $52,83 \mathrm{abc}$ & $42,68 b$ & $26,94 d$ & $13,65 \mathrm{bc}$ & 0,00 \\
\hline & $(70,53)$ & $(63,50)$ & $(45,96)$ & $(20,53)$ & $(5,57)$ & $(0,00)$ \\
\hline \multirow[t]{2}{*}{ 8. LG ROGERS } & $72,63 a$ & $60,71 \mathrm{a}$ & $51,13 \mathrm{ab}$ & $40,66 a b$ & $11,10 b c$ & 0,00 \\
\hline & $(91,09)$ & $(76,07)$ & $(60,62)$ & $(42,45)$ & $(3,71)$ & $(0,00)$ \\
\hline \multirow[t]{2}{*}{ 9.CNPA 86-1195-1 } & $54,89 \mathrm{~cd}$ & $45,00 \mathrm{c}$ & $43,85 b$ & $25,80 \mathrm{~d}$ & $13,23 b c$ & 0,00 \\
\hline & $(66,92)$ & $(50,00)$ & $(47,99)$ & $(18,94)$ & $(5,24)$ & $(0,00)$ \\
\hline 10. CNPA 86-1190-5 & $64,36 a b c$ & $53,28 \mathrm{abc}$ & $47,59 \mathrm{ab}$ & $29,48 \mathrm{~cd}$ & $11,56 \mathrm{bc}$ & 0,00 \\
\hline
\end{tabular}

Médias seguidas pela mesma letra minúscula, na vertical, não diferem estatisticamente, pelo teste de Tukey, a nível de 0,05 de probabilidade. Entre parênteses, dados originais (percentagem de plântulas normais)

Tabela 3. Valores médios de plântulas anormais, no vigésimo dia (3ª contagem) dos dez genótipos de algodoeiro herbáceo em seis níveis de polietileno glicol-6000

\begin{tabular}{|c|c|c|c|c|c|c|}
\hline \multirow[b]{2}{*}{ Genótipos } & \multicolumn{6}{|c|}{ Níveis de PEG-6000 (MPa) } \\
\hline & 0,0 & $-0,2$ & $-0,4$ & $-0,6$ & $-0,8$ & $-1,0$ \\
\hline \multirow[t]{2}{*}{ 1. CNPA 7H } & $12,11 \mathrm{~b}$ & $19,55 \mathrm{ab}$ & $18,21 \mathrm{a}$ & $18,75 a$ & $10,69 a b$ & $4,07 \mathrm{c}$ \\
\hline & $(4,40)$ & $(11,20)$ & $(9,77)$ & $(10,33)$ & $(3,44)$ & $(0,50)$ \\
\hline \multirow[t]{2}{*}{ 2. CNPA Precoce 1} & $29,71 \mathrm{a}$ & $28,29 \mathrm{a}$ & $21,77 \mathrm{a}$ & $18,51 \mathrm{ca}$ & $15,61 \mathrm{a}$ & $22,44 a$ \\
\hline & $(24,56)$ & $(22,46)$ & $(13,76)$ & $(10,08)$ & $(7,24)$ & $(14,57)$ \\
\hline \multirow[t]{2}{*}{ 3. CNPA Precoce 2} & $17,39 b$ & $22,69 a b$ & $16,76 \mathrm{a}$ & $15,42 \mathrm{a}$ & $14,08 \mathrm{a}$ & $15,42 \mathrm{ab}$ \\
\hline & $(8,93)$ & $(14,88)$ & $(8,32)$ & $(7,07)$ & $(5,92)$ & $(7,07)$ \\
\hline \multirow[t]{2}{*}{ 4. .IAC 22} & $15,27 b$ & $15,15 b$ & $14,95 \mathrm{a}$ & $15,61 \mathrm{a}$ & $0,00 \mathrm{~b}$ & $0,00 \mathrm{c}$ \\
\hline & $(6,94)$ & $(6,83)$ & $(6,66)$ & $(7,24)$ & $(0,00)$ & $(0,00)$ \\
\hline \multirow[t]{2}{*}{ 5. CNPA 87-62 } & $11,18 \mathrm{~b}$ & $19,36 a b$ & $15,25 \mathrm{a}$ & $19,86 \mathrm{a}$ & $4,92 \mathrm{ab}$ & $4,07 \mathrm{c}$ \\
\hline & $(3,76)$ & $(10,99)$ & $(6,92)$ & $(11,54)$ & $(0,74)$ & $(0,50)$ \\
\hline \multirow[t]{2}{*}{ 6. CNPA 87-33 } & $9,16 b$ & $13,92 b$ & $17,39 \mathrm{a}$ & $20,66 a$ & $2,88 \mathrm{~b}$ & $0,00 \mathrm{c}$ \\
\hline & $(2,53)$ & $(5,79)$ & $(8,93)$ & $(12,45)$ & $(0,25)$ & $(0,00)$ \\
\hline \multirow[t]{2}{*}{ 7. CNPA $87-24$} & $14,08 b$ & $15,45 b$ & $14,08 \mathrm{a}$ & $24,89 a$ & $8,46 a b$ & $0,00 \mathrm{c}$ \\
\hline & $(5,92)$ & $(7,10)$ & $(5,92)$ & $(17,71)$ & $(2,16)$ & $(0,00)$ \\
\hline \multirow[t]{2}{*}{ 8. LG ROGERS } & $6,95 b$ & $12,01 \mathrm{~b}$ & $15,81 \mathrm{a}$ & $19,60 \mathrm{a}$ & $6,95 \mathrm{ab}$ & $0,00 \mathrm{c}$ \\
\hline & $(1,46)$ & $(4,33)$ & $(7,42)$ & $(11,25)$ & $(1,46)$ & $(0,00)$ \\
\hline \multirow[t]{2}{*}{ 9. CNPA 86-1195-1 } & $16,84 b$ & $21,24 \mathrm{ab}$ & $18,29 \mathrm{a}$ & $19,70 \mathrm{a}$ & $15,21 \mathrm{a}$ & $0,00 \mathrm{c}$ \\
\hline & $(8,39)$ & $(13,12)$ & $(9,85)$ & $(11,36)$ & $(6,88)$ & $(0,00)$ \\
\hline \multirow[t]{2}{*}{ J.CNPA 86-1190-5 } & $9,53 \mathrm{Bb}$ & $15,49 b$ & $13,79 \mathrm{a}$ & $20,06 \mathrm{a}$ & $15,37 \mathrm{a}$ & $6,95 \mathrm{bc}$ \\
\hline & $(2,74)$ & $(7,13)$ & $(5,68)$ & $(11,77)$ & $(7,03)$ & $(1,46)$ \\
\hline
\end{tabular}



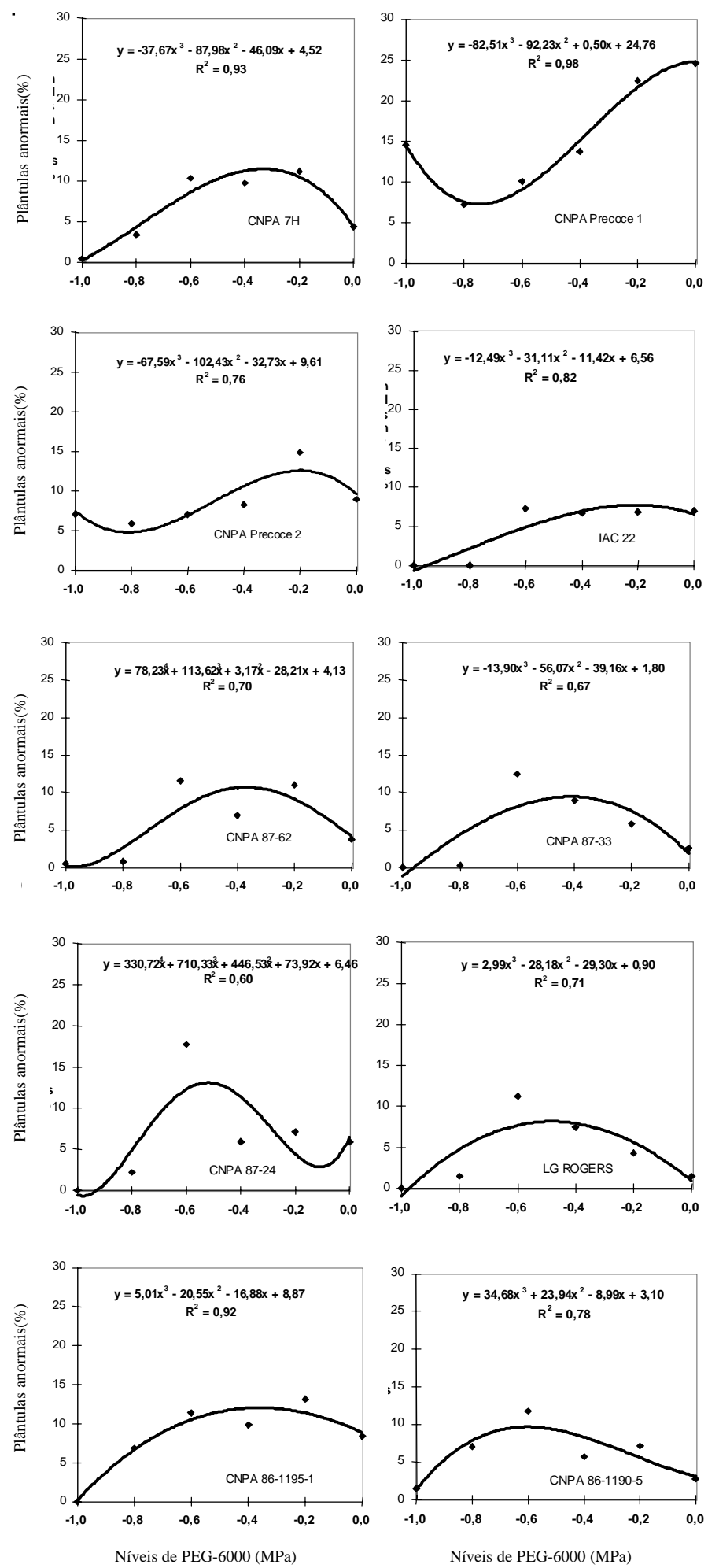

Figura 1. Valores médios de plântulas anormais, na terceira contagem, dos dez genótipos de algodoeiro herbáceo em seis níveis de polietileno glicol-6000

Aqueles autores citam, ainda, que a disponibilidade de $\mathrm{O}_{2}$, em soluções de PEG 6000, só se torna severamente limitante (solubilidade relativa $=20 \%$ ) quando o potencial osmótico atinge cerca de -7 bars.

Observa-se, também, que a cultivar CNPA Precoce 1 apresentou a maior taxa de anormalidades, em todos os níveis estudados, indicando que, embora tenha sido o genótipo mais contaminado por patógenos, conseguiu germinar, mesmo nos níveis mais altos de estresse (Tabela 2 e Tabela 3 ).
A análise de regressão polinomial aplicada aos dados da Tabela 3, referentes à terceira contagem, possibilitou a obtenção de equações correlacionando os níveis de potenciais osmóticos com os percentuais de plântulas anormais, conforme apresentadas na Figura 1. Observa-se, em geral, um bom ajuste entre essas variáveis, expresso pelo coeficiente de determinação $\mathrm{R}^{2}$, permitindo estimar-se a percentagem de anormalidades de plântulas de cada genótipo estudado, em função do potencial de água do substrato.

Considerando-se, aqui, que maior taxa de anormalidade significa nível de umidade ainda suficiente para germinação (plântulas anormais são sementes que germinaram mas, por apresentarem lesões fúngicas ou bacterianas, não entram no boletim do teste de germinação), pode-se classificar como mais sensíveis, os genótipos IAC 22, CNPA 87-33, CNPA 87-24 e CNPA 86-1195-1 (tiveram germinação inibida antes de chegar a -1,0MPa, conforme Figura 1) e as cultivares CNPA Precoce 2 e CNPA Precoce 1, como menos sensíveis (ainda apresentaram níveis de anormalidades em -1,0MPa), pois foram mais sujeitas a infecções, devido à sua contaminação original enquanto CNPA 7H, CNPA 86-1190-5 e CNPA 87-62 podem ser consideradas medianamente sensíveis.

\section{Sementes deterioradas}

Os percentuais médios de sementes deterioradas avaliados na $3^{\text {a }}$ contagem do teste de germinação, estão distribuídos na Tabela 4 e representados na Figura 2.

Com o desdobramento da interação e aplicado o teste de Tukey, em nível de 0,05 de probabilidade, observa-se que a percentagem de sementes deterioradas dos vários genótipos variou com os diferentes níveis de potenciais simulados, havendo tendência de aumento até o $\mathrm{N}_{3}$ e, depois, decréscimo, à medida que se aumentava a concentração de PEG-6000 na solução (Figura 2), explicável pelo fato de que, em conteúdos de umidade no substrato, que apenas possibilite embebição precária e demorada, ocorre rápida deterioração das sementes (Tabela 4) e grande parte delas não consegue germinar (Tabelas 2 e 3); isto foi o que ocorreu no $\mathrm{N}_{2}$ e no $\mathrm{N}_{3}$, em relação ao tratamento testemunha $\left(\mathrm{N}_{1}\right)$; já no tratamento testemunha $(0,0 \mathrm{MPa})$ a taxa de embebição foi plenamente satisfeita desde os primeiros dias pós-semeadura, com as sementes germinando rapidamente, não ficando sujeitas, por mais tempo, à ação dos patógenos; nos mais baixos potenciais osmóticos $\left(\mathrm{N}_{4}\right.$ a $\left.\mathrm{N}_{6}\right)$ por sua vez, a disponibilidade de umidade para entumescimento da semente e para multiplicação de patógenos foi crescentemente restringida (Tabela 4).

Estas considerações assemelham-se às evidenciadas por Hunter \& Erickson (1952) de que sementes colocadas em solo com umidade insuficiente para germinação são sujeitas a danos (infecções de partes ou de toda a plântula) ou destruição (deterioração ou perda total da capacidade germinativa) por patógenos do solo ou da própria semente.

No presente caso, a deterioração das sementes (Tabela 4) teve influência muito maior que a infecção de plântulas (Tabela 3) na capacidade germinativa total (Tabela 2) das sementes dos genótipos estudados, inclusive nos níveis mais altos de estresse, reforçando a hipótese da existência de grande contaminação inicial por patógenos da própria semente.

Queiroz (1995) por outro lado, estudando o efeito de seis níveis de PEG-6000 sobre a germinação de sementes de dez 
Tabela 4. Percentual de sementes deterioradas (3aㅗ contagem do teste de germinação) dos dez genótipos de algodoeiro herbáceo em seis níveis de polietileno glicol-6000

\begin{tabular}{|c|c|c|c|c|c|c|}
\hline \multirow[t]{2}{*}{ Genótipos } & \multicolumn{6}{|c|}{ Níveis de PEG-6000 (MPa) } \\
\hline & 0,0 & $-0,2$ & $-0,4$ & $-0,6$ & $-0,8$ & $-1,0$ \\
\hline \multirow[t]{2}{*}{ 1. CNPA $7 \mathrm{H}$} & $24,09 \mathrm{ab}$ & $34,07 \mathrm{a}$ & $32,86 \mathrm{ab}$ & $29,23 \mathrm{ab}$ & $31,58 \mathrm{ab}$ & $12,86 \mathrm{a}$ \\
\hline & $(16,66)$ & $(31,38)$ & $(29,44)$ & $(23,85)$ & $(27,42)$ & $(4,95)$ \\
\hline \multirow[t]{2}{*}{ 2. CNPA Precoce 1} & $23,49 \mathrm{abc}$ & $28,72 \mathrm{ab}$ & $31,83 \mathrm{ab}$ & $29,58 \mathrm{ab}$ & $32,17 \mathrm{a}$ & $20,10 \mathrm{a}$ \\
\hline & $(15,89)$ & $(23,09)$ & $(27,82)$ & $(24,37)$ & $(28,35)$ & $(11,81)$ \\
\hline \multirow[t]{2}{*}{ 3. CNPA Precoce 2} & $13,13 \mathrm{~d}$ & $19,69 \mathrm{c}$ & $25,81 b$ & $26,15 \mathrm{ab}$ & $23,56 \mathrm{bcd}$ & $14,74 \mathrm{a}$ \\
\hline & $(5,16)$ & $(11,35)$ & $(18,96)$ & $(19,42)$ & $(15,98)$ & $(6,47)$ \\
\hline \multirow[t]{2}{*}{ 4. IAC 22} & $20,5 \mathrm{bcd}$ & $28,61 \mathrm{ab}$ & $26,15 b$ & $23,73 b$ & $22,9 \mathrm{~cd}$ & $17,13 \mathrm{a}$ \\
\hline & $(12,23)$ & $(22,93)$ & $(19,42)$ & $(16,19)$ & $(15,13)$ & $(8,68)$ \\
\hline \multirow[t]{2}{*}{ 5. CNPA $87-62$} & $20,73 \mathrm{bcd}$ & $32,88 \mathrm{a}$ & $30,91 \mathrm{ab}$ & $24,11 b$ & $22,65 \mathrm{~cd}$ & $17,83 \mathrm{a}$ \\
\hline & $(12,53)$ & $(29,47)$ & $(26,39)$ & $(16,69)$ & $(14,83)$ & $(9,38)$ \\
\hline \multirow[t]{2}{*}{ 6. CNPA $87-33$} & $24,91 \mathrm{ab}$ & $29,53 \mathrm{ab}$ & $29,38 \mathrm{ab}$ & $33,49 a$ & $22,48 \mathrm{~cd}$ & $12,86 \mathrm{a}$ \\
\hline & $(17,74)$ & $(24,29)$ & $(24,07)$ & $(30,45)$ & $(14,62)$ & $(4,95)$ \\
\hline \multirow[t]{2}{*}{ 7. CNPA $87-24$} & $28,14 \mathrm{ab}$ & $29,56 a b$ & $35,01 \mathrm{a}$ & $25,81 \mathrm{ab}$ & $24,7 \mathrm{abcd}$ & $18,66 \mathrm{a}$ \\
\hline & $(22,24)$ & $(24,34)$ & $(32,92)$ & $(18,96)$ & $(17,40)$ & $(10,24)$ \\
\hline \multirow[t]{2}{*}{ 8. LG ROGERS } & $15,15 \mathrm{~cd}$ & $23,12 b c$ & $24,95 b$ & $21,95 b$ & $16,59 \mathrm{~cd}$ & $14,74 \mathrm{a}$ \\
\hline & $(6,83)$ & $(15,42)$ & $(17,79)$ & $(13,97)$ & $(08,15)$ & $(6,47)$ \\
\hline \multirow[t]{2}{*}{ 9. CNPA 86-1195-1 } & $29,40 \mathrm{a}$ & $35,25 a$ & $32,49 \mathrm{ab}$ & $28,86 \mathrm{ab}$ & $30,85 \mathrm{abc}$ & $15,81 \mathrm{a}$ \\
\hline & $(24,10)$ & $(33,31)$ & $(28,85)$ & $(23,30)$ & $(26,30)$ & $(7,42)$ \\
\hline \multirow[t]{2}{*}{ 10.CNPA 86-1190-5 } & $22,73 a b c$ & $27,3 \mathrm{abc}$ & $31,85 \mathrm{ab}$ & $28,82 \mathrm{ab}$ & $28,6 a b c$ & $15,71 \mathrm{a}$ \\
\hline & $(14,93)$ & $(20,98)$ & $(27,85)$ & $(23,24)$ & $(22,87)$ & $(7,33)$ \\
\hline
\end{tabular}

Médias seguidas pela mesma letra minúscula, na vertical, não diferem estatisticamente, pelo teste de Tukey, a nível de 0,05 de probabilidade. Entre parênteses, dados originais (percentagem de sementes infectadas)

cultivares de feijão, observou que o percentual de infecção aumentou progressivamente a medida em que se elevaram os níveis de pressão osmótica.

A partir dos dados da Tabela 4, foram realizados estudos de regressão e obtidas equações, correlacionando percentuais de sementes deterioradas com níveis de potenciais osmóticos, apresentadas na Figura 2. Pelos valores do coeficiente de determinação $\mathrm{R}^{2}$, superiores a $79 \%$, verifica-se um bom ajuste entre essas variáveis, permitindo estimar-se a percentagem de sementes deterioradas de cada genótipo, em função do conteúdo de água no substrato.

Pelos dados de deterioração de sementes, pode-se classificar as cultivares CNPA Precoce 2 e LG ROGERS, como potencialmente menos sensíveis (houve embebição de umidade suficiente para a germinação) pois apresentaram os menores percentuais de deterioração em todos os níveis, sendo a cultivar CNPA Precoce 1 a mais sensível, por apresentar os maiores índices de deterioração nos níveis de maior estresse, enquanto os genótipos IAC 22, CNPA 7H, CNPA 87-62, CNPA 87-24, CNPA 87-33 e CNPA 86-1190-5, foram medianamente sensíveis.

\section{Sementes duras}

Após desdobramento da interação, são apresentados, na Tabela 5, os percentuais médios de sementes duras, na $3^{\mathrm{a}}$ contagem do teste de germinação, dos dez genótipos de algodoeiro herbáceo, em seis níveis de polietileno glicol-6000, melhor visualizados na Figura 3.

A percentagem de sementes duras dos diferentes genótipos estudados variou com os vários níveis de potenciais, havendo tendência de aumento, a medida em que foi elevada a concentração de PEG-6000 na solução (Figura 3).

O endurecimento de sementes de algodão caracteriza-se pelo não inchamento (embebição) das mesmas. Quanto maior a percentagem de sementes duras, maior o efeito do nível de estresse hídrico sobre o genótipo, ou seja, com aumento da concentração de PEG-6000 na solução e, consequentemente, diminuição crescente da quantidade de água disponível para embebição, houve, como esperado, um aumento progressivo do percentual de sementes duras; essas sementes são ainda viáveis e provavelmente não germinaram porque não lhes foram oferecidas as condições mínimas de umidade. Estas observações concordam com afirmações contidas em Parmer \& Moore (1968) e Singh \& Singh (1983b) de que a absorção de água pela semente é diminuída com o aumento da pressão osmótica.

No nível testemunha, não foi constatada a presença de sementes duras em nenhum dos genótipos (Tabela 5) indicando que as respectivas sementes ou "germinaram" (plântulas normais - Tabela 2, ou plântulas anormais - Tabela 3), ou se deterioraram (Tabela 4).

Aplicando-se análise de regressão aos dados da Tabela 5, foram obtidas as equações contidas na Figura 3, correlacionando-se percentuais de sementes duras com níveis de potenciais osmóticos. Há uma boa combinação entre essas variáveis, expressa pelo coeficiente de determinação $\mathrm{R}^{2}$, superior a $93 \%$, sendo possível estimar a percentagem de sementes duras de sementes de cada genótipo estudado, em função do potencial de água do substrato.

A cultivar CNPA Precoce 2 foi o genótipo com menores percentuais de sementes duras, em praticamente todos os níveis 

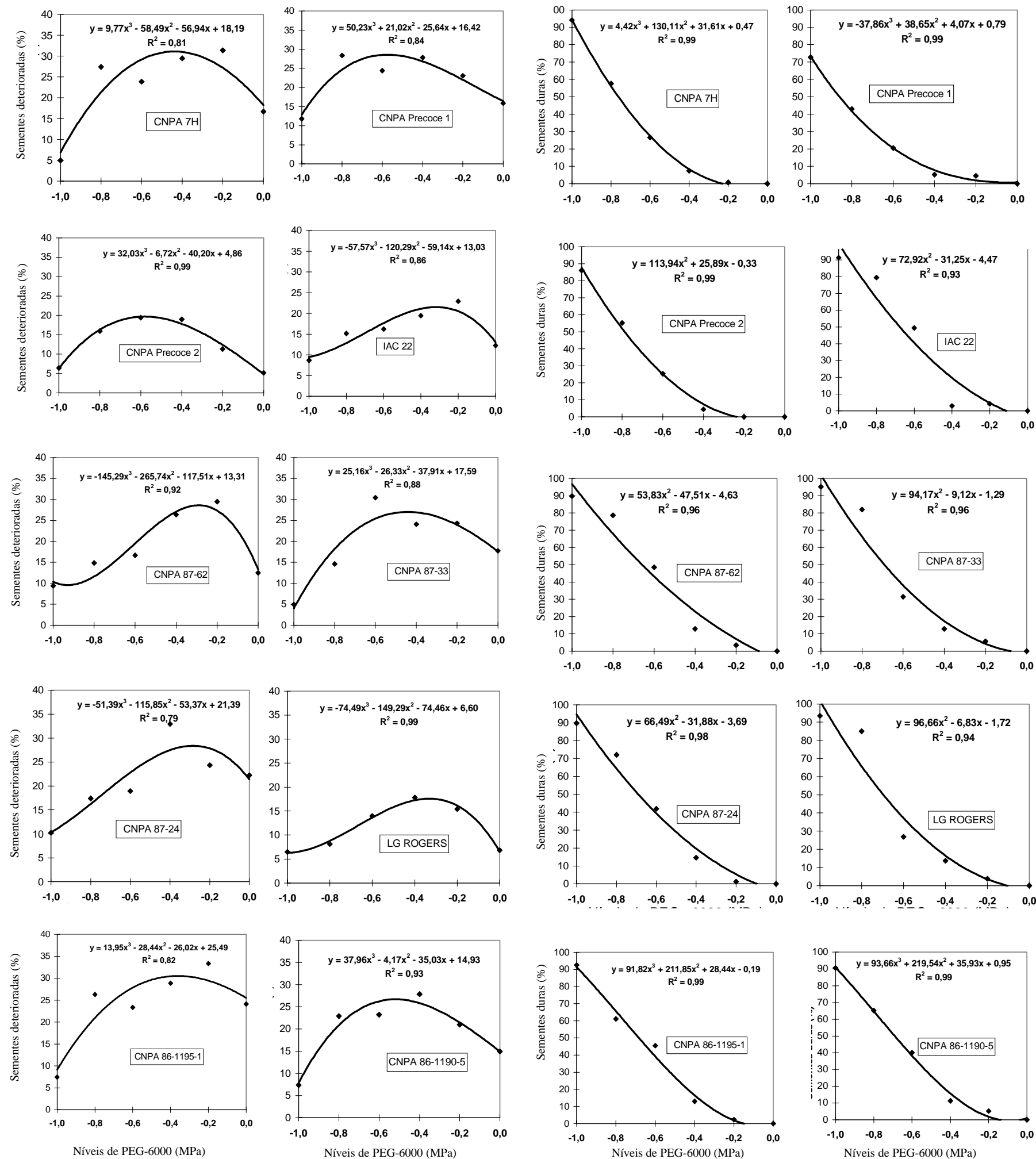

Figura 2. Percentual de sementes deterioradas (3a. contagem do teste de germinação) dos dez genótipos de algodoeiro herbáceo em seis níveis de polietileno glicol-6000

do $\mathrm{N}_{2}(-0,2 \mathrm{MPa})$ ao $\mathrm{N}_{5}(-0,8 \mathrm{MPa})$ indicando, assim, que sua capacidade germinativa foi a menos afetada pela diminuição crescente da tensão osmótica; em seguida vem a cultivar CNPA Precoce 1, destacando-se, entre todas, nos níveis $\mathrm{N}_{4}(-0,6 \mathrm{MPa})$, $\mathrm{N}_{5}$ e $\mathrm{N}_{6}$, onde se sobressaiu, também, a cultivar CNPA $7 \mathrm{H}$.

Finalmente, verifica-se que nos mais altos níveis de estresse $\left(\mathrm{N}_{4}, \mathrm{~N}_{5}\right.$ e $\left.\mathrm{N}_{6}\right)$ o percentual de endurecimento (Tabela 5) supera o de "germinação" (plântulas normais - Tabela 2, e plântulas
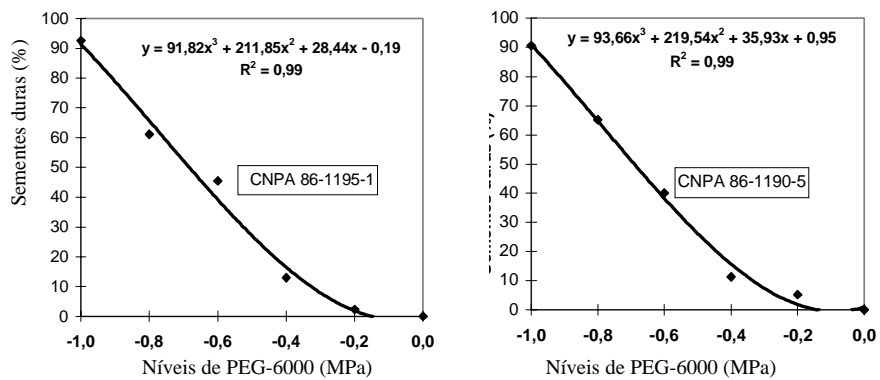

Figura 3. Percentagem média de sementes duras, na 3a. contagem do teste de germinação, dos dez genótipos de algodoeiro herbáceo em seis níveis de polietileno glicol-6000

anormais - Tabela 3) e de deterioração das sementes (Tabela 4); esta evidência reforça a premissa de que a diminuição desses percentuais (de germinação propriamente dita, de anormalidades em plântulas e de deterioração das sementes) nos vários genótipos estudados, decorre da diminuição da absorção de água para embebição (entumescimento) das sementes, crescentemente restringida pelo aumento da concentração de PEG-6000. 
Tabela 5. Percentagem média de sementes duras, na 3a contagem do teste de germinação, dos dez genótipos de algodoeiro herbáceo, em seis níveis de polietileno glicol-6000

\begin{tabular}{|c|c|c|c|c|c|c|}
\hline \multirow[t]{2}{*}{ Genótipos } & \multicolumn{6}{|c|}{ Níveis de PEG-6000 (MPa) } \\
\hline & 0,0 & $-0,2$ & $-0,4$ & $-0,6$ & $-0,8$ & $-1,0$ \\
\hline \multirow[t]{2}{*}{ 1. CNPA $7 \mathrm{H}$} & 0,00 & $4,92 \mathrm{ab}$ & $15,77 \mathrm{abcd}$ & $30,98 \mathrm{~cd}$ & 49,35 cde & $75,92 \mathrm{ab}$ \\
\hline & $(0,00)$ & $(0,74)$ & $(7,39)$ & $(26,50)$ & $(57,56)$ & $(94,08)$ \\
\hline \multirow[t]{2}{*}{ 2. CNPA Precoce 1} & 0,00 & $12,22 \mathrm{a}$ & $13,07 \mathrm{bcd}$ & $26,90 \mathrm{~d}$ & $40,96 \mathrm{e}$ & $58,51 \mathrm{c}$ \\
\hline & $(0,00)$ & $(4,48)$ & $(5,11)$ & $(20,47)$ & $(42,97)$ & $(72,72)$ \\
\hline \multirow[t]{2}{*}{ 3. CNPA Precoce 2} & 0,00 & $0,00 \mathrm{~b}$ & $12,16 \mathrm{~cd}$ & $30,31 \mathrm{~cd}$ & 47,93de & $68,02 b$ \\
\hline & $(0,00)$ & $(0,00)$ & $(4,44)$ & $(25,47)$ & $(55,10)$ & $(85,99)$ \\
\hline \multirow[t]{2}{*}{ 4. IAC 22} & 0,00 & $11,76 \mathrm{a}$ & $9,84 d$ & $44,71 \mathrm{a}$ & $63,06 a$ & $72,87 \mathrm{ab}$ \\
\hline & $(0,00)$ & $(4,15)$ & $(2,92)$ & $(49,49)$ & $(79,47)$ & $(91,32)$ \\
\hline \multirow[t]{2}{*}{ 5. CNPA $87-62$} & 0,00 & $10,75 \mathrm{a}$ & $21,06 \mathrm{abc}$ & $44,14 \mathrm{a}$ & $62,47 \mathrm{ab}$ & $71,25 \mathrm{ab}$ \\
\hline & $(0,00)$ & $(3,48)$ & $(12,91)$ & $(48,50)$ & $(78,64)$ & $(89,67)$ \\
\hline \multirow[t]{2}{*}{ 6. CNPA 87-33 } & 0,00 & $13,63 \mathrm{a}$ & $20,97 \mathrm{abc}$ & $34,07 \mathrm{bcd}$ & $64,87 \mathrm{a}$ & $77,14 \mathrm{a}$ \\
\hline & $(0,00)$ & $(5,55)$ & $(12,81)$ & $(31,38)$ & $(81,97)$ & $(95,05)$ \\
\hline \multirow[t]{2}{*}{ 7. CNPA 87-24 } & 0,00 & $6,43 \mathrm{ab}$ & $22,55 \mathrm{a}$ & $40,36 \mathrm{ab}$ & $58,11 \mathrm{abc}$ & $71,35 \mathrm{ab}$ \\
\hline & $(0,00)$ & $(1,25)$ & $(14,71)$ & $(41,94)$ & $(72,09)$ & $(89,77)$ \\
\hline \multirow[t]{2}{*}{ 8. LG ROGERS } & 0,00 & $11,16 \mathrm{a}$ & $21,73 \mathrm{ab}$ & $31,24 \mathrm{~cd}$ & $67,17 \mathrm{a}$ & $75,26 \mathrm{ab}$ \\
\hline & $(0,00)$ & $(3,75)$ & $(13,71)$ & $(26,90)$ & $(84,95)$ & $(93,53)$ \\
\hline \multirow[t]{2}{*}{ 9. CNPA 86-1195-1 } & 0,00 & $8,65 \mathrm{ab}$ & $21,06 a b c$ & $42,39 \mathrm{ab}$ & $51,43 \mathrm{~cd}$ & $74,19 \mathrm{ab}$ \\
\hline & $(0,00)$ & $(2,26)$ & $(12,91)$ & $(45,45)$ & $(61,13)$ & $(92,58)$ \\
\hline \multirow[t]{2}{*}{ 10. CNPA 86-1190-5 } & 0,00 & $13,26 \mathrm{a}$ & $19,68 \mathrm{abc}$ & $39,23 \mathrm{abc}$ & $53,81 \mathrm{bcd}$ & $72,11 \mathrm{ab}$ \\
\hline & $(0,00)$ & $(5,26)$ & $(11,34)$ & $(40,00)$ & $(65,14)$ & $(90,56)$ \\
\hline
\end{tabular}

Médias seguidas pela mesma letra minúscula, na vertical, não diferem estatisticamente, pelo teste de Tukey, a nível de 0,05 de probabilidade. Entre parênteses, dados originais (percentagem de sementes duras)

\section{CONCLUSÕES}

1. Os genótipos de algodoeiro herbáceo em estudo apresentam comportamento diferenciado nos vários níveis de estresse hídrico simulado pelo polietileno-glicol-6000.

2. O decréscimo da percentagem de sementes deterioradas e de plântulas anormais e o aumento da percentagem de sementes duras, nos genótipos de algodoeiro herbáceo em estudo, a medida em que aumenta a pressão osmótica da solução, decorre da diminuição da absorção de água para embebição (entumescimento) das sementes.

3. As cultivares CNPA Precoce 2 e CNPA Precoce 1 são as menos sensíveis aos baixos potenciais osmóticos (-0,6 e -0,8 $\mathrm{MPa}$ ) enquanto LG ROGERS e CNPA 7H são medianamente sensíveis.

4. O genótipo mais afetado pelos níveis crescentes de estresse hídrico é a linhagem CNPA 86-1195-1.

\section{RECOMENDAÇÕES}

Deslintar as sementes de algodão e tratá-las com fungicidas, antes da instalação dos testes, para se evitar a multiplicação de patógenos.

Programar a instalação dos diferentes níveis de simulação de estresse para um só dia, reservando-se os conjuntos para se fazer contagens e medições em dias consecutivos, evitando a manipulação constante por certo tempo, em vista do risco da proliferação por patógenos.

Selar, com plástico, o conjunto de sementes para evitar a evaporação de água e, consequentemente, a possível variação do potencial de água da solução de PEG.

\section{AGRADECIMENTOS}

À Embrapa Algodão, pela cessão das sementes (Pesquisador Joaquim Nunes da Costa) e ao Laboratório de Análises de Sementes (Chefe Geral Napoleão Esberard de Macêdo Beltrão); à CAPES e à COPEAg/CCT/UFPB pelo apoio financeiro ao projeto de pesquisa.

\section{REFERÊNCIAS BIBLIOGRÁFICAS}

ALMEIDA, F. de A.C.; MATA, M.E.R.M.C.; MARTINS, J.H. Dormência das sementes de algodão sob condições controladas de armazenamento. Revista Nordestina de Armazenagem, v.2, n.1, p.22-36, 1985.

AMORIM NETO, M. da S.; MEDEIROS, J. da C.; BELTRÃO, N.E. de M.; FREIRE, E.C.; NOVAES FILHO, M. de B.; GOMES, D.C. Zoneamento para a cultura do algodão no Nordeste. II. Algodão herbáceo. Campina Grande: EMBRAPA-CNPA, 1997. 31p. (EMBRAPA-CNPA. Boletim de Pesquisa, 35).

BANZATTO, D.A.; KRONKA, S. do N. Experimentação agrícola. Jaboticabal: FUNEP, 1989. 247p.

BARRETO, A.N.; BEZERRA, J.R.C.; LUZ, M.J. da S. e; AMORIM NETO, M. da S. Irrigação por bacias em nível na cultura do algodoeiro. Campina Grande: EMBRAPACNPA, 1997. 31p. (EMBRAPA-CNPA. Circular Técnica, 26).

BEWLEY, J.D.; BLACK, M. Seeds: physiology of development and germination. 2ed. New York: Plenum Press, 1985. 367p. 
BRADFORD, K.J. Manipulation of seed water relations via osmotic priming to improve germination under stress conditions. Hortscience, Alexandria, v.21, n.5, p.1105-1112, 1986.

BRASIL. Ministério da Agricultura. Departamento de Produção Vegetal, Divisão de Sementes e Mudas. Regras para análise de sementes. Brasília: LANARV/SNAD/MA, 1992. 188p.

CAMPOS, I.S.; ASSUNÇÃO, M.V. Estresse salino e hídrico na germinação e vigor do arroz. Pesquisa Agropecuária Brasileira, Brasília, v.25, n.6, p.857-862, 1990.

CARVALHO, N.M.; NAKAGAWA, J. Sementes: ciência, tecnologia e produção. 3.ed. Campinas: CARGILL, 1980. $326 \mathrm{p}$.

EVANS, W.F.; STICKLER, F.C. Grain sorghum seed germination under moisture and temperature stresses. Agronomy Journal, Madison, v.53, n.6, p.369-372, 1961.

FIEGENBAUM, V.; SANTOS, D.S.B. dos; MELLO, V.D.C.; SANTOS FILHO, B.G. dos; TILLMANN, M.A.A.; SILVA, J.B. da. Influência do déficit hídrico sobre os componentes de rendimento de três cultivares de feijão. Pesquisa Agropecuária Brasileira, Brasília, v.26, n.2, p.275-280, 1991.

HADAS, A. A suggested method for testing seed vigour under water stress in simulated arid conditions. Seed Science \& Technology, v.5, p.519-525, 1977.

HUNTER, J.R.; ERICKSON, A.E. Relation of seed germination to soil moisture tension. Agronomy Journal, Madison, v.44, n.3, p.107-109, 1952.

JENSEN, R.D. Effects of soil water tension on the emergence and growth of cotton seedlings. Agronomy Journal, Madison, v.63, p.766-768, 1971.

KRZYZANOWKI, F.C.; FRANÇA NETO, J.P.; HENNING, A.A. Relato dos testes de vigor disponíveis para as grandes culturas. Informativo ABRATES, v.1, n.2, p.42-47, 1991.

LAGERWERFF, J.W.; OGATA, G.; EAGLE, H.E. Control of osmotic pressure of culture solutions with polyethylenoglicol. Science, v.133 , n.3463, p.1486-1487, 1961.

LAWLOR, D.W. Absorption of polyethylenoglicols by plants and their effects on plant growth. New Phytologist, v.69, p.501-513, 1970.

LEVITT, J. Response of plants to environmental stresses. New York: Academic Press, 1972. 697p.

LOPES, G.M.B.; PIMENTEL, M. de L.; MIRANDA, P.; REIS, O.V. dos. Efeito do déficit hídrico induzido pelo manitol e cloreto de sódio na germinação de sementes de feijão (Phaseolus vulgaris L.). Pesquisa Agropecuária Pernambucana, Recife, v.6, n.especial, p.49-59, 1989.

MATA, M.E.R.M.C.; ALMEIDA, F. de A.C.; MARTINS, J.H. Deterioração de sementes armazenadas de algodão (Gossypium hirsutum L. r. latifolium H.). Revista Nordestina de Armazenagem, v.2, n.1, p.37-56, 1985.
METIVIER, J.R. Dormência e germinação. In: FERRI, M.G. Fisiologia vegetal. São Paulo: EPV/EDUSP, v.2, 1979. p.343-392.

MEXAL, J.; FISHER, J.T.; OSTERYOUNG, J.; REID, P.C.P. Oxygen availability in polyethylene glycol solutions and its implication in plant water relations. Plant Physiology, v.55, p.20-24, 1975.

NIENOW, A.W; BUJALSKI, W.; PETCH, G.M.; GRAY, D.; DREW, R.L.K. Bulk priming and drying of leek seeds: the effects of two polymers of polyethylene glycol and fluidised bed drying. Seed Science \& Technology, v.19, p.107-116, 1991.

NÓBREGA, L.H.P.; RODRIGUES, T. de J.D. Efeitos do estresse hídrico sobre a absorção de água durante a germinação de sementes e o estabelecimento de plântulas de soja. Informativo ABRATES, v.5, n.1, p.51-58, 1995.

NOGUEIRA, S. dos S.S.; NAGAI, V. Deficiência hídrica simulada nos diferentes estádios de desenvolvimento de um cultivar precoce de soja. Bragantia, Campinas, v.47, n.1, p.9-14, 1988.

PARMER, M.Y; MOORE, R.P. Carbowax 6000, manitol and sodium chloride for simulating drought conditions in germination studies of corn (Zea mays L.) of stron and weak vigor. Agronomy Journal, Madison, v.60, n.2, p.192-195, 1968.

POPINIGIS, F. Fisiologia da semente. Brasília: AGIPLAN, 1977. 289p.

QUEIROZ, M.F. de. Germinação e vigor de sementes de Phaseolus vulgaris L. em diferentes potenciais osmóticos induzidos por polietileno glicol-6000. Campina Grande: UFPB/CCT/DEAG, 1995. 106p. Dissertação de Mestrado.

SHARMA, M.L. Simulation of drought and its effect on germination of five pasture species. Agronomy Journal, Madison, v.65, p.982-987, 1973.

SHARMA, M.L. Interaction of water potential and temperature effects on germination of three semi-arid plant species. Agronomy Journal, Madison, v.68, p.390-394, 1976.

SINGH, K.P.; SINGH, K. Seed germination and seedling growth responses of some rice cultivars to water potential treatments. Indian Journal Plant Physiology, v.26, n.2, p.182-188, 1983a.

SINGH, K.P.; SINGH, K. Water uptake and germination de wheat seeds under different external water potentials in osmoticum solutions. Seed Research, v.11, n.1, p.13-19, $1983 b$.

VILLELA, F.A.; DONI FILHO, L.; SIQUEIRA, E.L. Tabela de potencial osmótico em função da concentração de polietileno glicol 6000 e da temperatura. Pesquisa Agropecuária Brasileira, Brasília, v.26, n.11/12, p.19571968, 1991. 